\title{
Straingauge plethysmography in the assessment of joint inflammation
}

\author{
I. VADASZ \\ Department of Physical Medicine and Rheumatology, Guy's Hospital, London
}

The quantitation of joint inflammation poses many problems. Such a measurement would be very useful, particularly in the objective assessment of changes in inflammatory activity in response to treatment.

With current methods of assessment it is often difficult to distinguish between the analgesic and the anti-inflammatory activity of drugs. Pain on movement or tenderness on pressure, so often regarded as a measure of 'activity', can be diminished by a purely analgesic substance, and these methods of assessment are, at least in part, subjective.

The grip strength test, while providing a numerical index, depends on a number of factors including the co-operation of the patient, and it can also be influenced by a purely analgesic substance.

Swelling can be measured, for example by ring size (Boardman and Hart, 1967) and used in the assessment, but joint size may not necessarily correlate accurately with inflammation.

Since hyperaemia is such a constant feature of inflammation, a better method of assessment would be one based on a measurement of blood flow through and around the joint. Changes in the rate of flow must surely mirror fluctuations in the inflammatory process.

The use of the measurement of intra-articular temperature (Horvath and Hollander, 1949), which is indirectly related to blood flow, has been explored and a good correlation found with the degree of inflammation, but as it is necessary to insert thermocouple electrodes into the joints, the method is not very practical.

Estimating the flow by measuring the rate at which a radioactive substance is cleared from a joint is a satisfactory alternative method (Dick, Dick, Nuki, Whaley, Boyle, Shenkin, Downie and Buchanan, 1969), but once again the joint has to be punctured and radio-isotopes have to be available.

In limbs the blood flow can be measured easily and accurately by venous occlusive plethysmography. The method using a mercury straingauge described by Whitney (1953) is simple and free of discomfort $\frac{0}{\omega}$ to the patient. This method of assessing joint inflammation has been investigated and the results are reported below.

\section{Method and material}

The equipment used consisted of straingauges made of mercury-filled silastic tubes, used with a Parks Electronics (Oregon) Model 270 Plethysmograph. This provides a $\overrightarrow{0}$ suitable direct current and means of balancing the circuit.

A Watanabe Miniwriter D.C. recorder was used to record changes in the current through the plethysmograph.

A small electric pump was used to inflate the venous tourniquet, which was an ordinary sphygmomanometer cuff arranged to release air after the pressure reaches a pre-set level $(60 \mathrm{~mm}$. $\mathrm{Hg})$.

With the straingauge around the joint the venous return from the limb was occluded several times for periods of 10 seconds. The increase in the circumference of the joint during venous occlusion was recorded. After calibration, the rate of increase in circumference and hence in the volume was calculated, and a measure of the blood flow obtained.

Blood flow measurements were made around the knee joints of patients suffering from rheumatoid arthritis and osteoarthrosis, with predominantly unilateral involvement. In this way the uninvolved knee acted as a control.

The involved knee was then injected with methylprednisolone $(80 \mathrm{mg}$.) and 2 per cent. lignocaine $(2 \mathrm{ml}$.$) , N$ and the measurement was repeated 1 week later.

Eleven patients with rheumatoid arthritis according to $N$ the ARA criteria (Ropes, Bennett, Cobb, Jacox, and N Jessar, 1959) and nine patients with osteoarthrosis were investigated. The blood flow was also measured in ten normal subjects to see if there was any difference between the two knees under normal circumstances.

In one patient with rheumatoid arthritis and in one normal subject serial measurements were made.

To test the consistency of the method, five different measurements were made on each knee in one subject in quick succession. 


\section{Results}

In normal subjects there was little or no difference between the blood flow in the two knees (Table I). The mean difference was near to zero with very small variability (S.E. \pm 0.027$)$. This suggests a consistent technique, but to assess this particular point explicitly a comparison was made of the variability of samples centered on different means. This showed the variability was consistent (Fisher's F test).

Table I Blood flows in normal subjects (ml./min./ $100 \mathrm{ml}$.)

\begin{tabular}{|c|c|c|c|}
\hline \multirow[t]{2}{*}{ Subject no. } & \multicolumn{2}{|l|}{ Knee } & \multirow[t]{2}{*}{ Difference } \\
\hline & Right & Left & \\
\hline $\begin{array}{r}1 \\
2 \\
3 \\
4 \\
5 \\
6 \\
7 \\
8 \\
9 \\
10\end{array}$ & $\begin{array}{l}0.87 \\
0.71 \\
0.78 \\
0.57 \\
0.48 \\
0.64 \\
0.79 \\
0.90 \\
0.92 \\
1.77\end{array}$ & $\begin{array}{l}1.02 \\
0.52 \\
0.84 \\
0.56 \\
0.45 \\
0.66 \\
0.79 \\
0.94 \\
0.89 \\
1.75\end{array}$ & $\begin{array}{c}-0.15 \\
+0.19 \\
-0.06 \\
+0.01 \\
+0.03 \\
-0.02 \\
0 \\
-0.04 \\
+0.03 \\
+0.02\end{array}$ \\
\hline \multicolumn{3}{|c|}{$P \doteqdot 0.5$ not significant } & $\begin{array}{r}\bar{x} 0.001 \\
\text { S.E. } 0.027 \\
\mathrm{t}=0.036\end{array}$ \\
\hline
\end{tabular}

In patients with rheumatoid arthritis the blood flow on the involved side was always higher than on the non-involved side (Table II). The mean difference between the two sides was large and significantly $(P<0.001)$ different from zero.

Table II Blood flow in patients with rheumatoid arthritis before treatment ( $\mathrm{ml} . / \mathrm{min} . / 100 \mathrm{ml}$.)

\begin{tabular}{|c|c|c|c|}
\hline \multirow[t]{2}{*}{ Patient no. } & \multicolumn{2}{|l|}{ Knee } & \multirow[t]{2}{*}{ Difference } \\
\hline & Involved & Non-involved & \\
\hline $\begin{array}{r}1 \\
2 \\
3 \\
4 \\
5 \\
6 \\
7 \\
8 \\
9 \\
10 \\
11 \\
\end{array}$ & $\begin{array}{l}2 \cdot 48 \\
1 \cdot 84 \\
2 \cdot 38 \\
1 \cdot 27 \\
1 \cdot 82 \\
2 \cdot 70 \\
6 \cdot 10 \\
1 \cdot 96 \\
2 \cdot 82 \\
2 \cdot 30 \\
2 \cdot 48\end{array}$ & $\begin{array}{l}1.40 \\
1.19 \\
0.69 \\
0.79 \\
0.99 \\
1.85 \\
2.78 \\
1.40 \\
0.99 \\
1.52 \\
1.40\end{array}$ & $\begin{array}{l}1.08 \\
0.65 \\
1.69 \\
0.57 \\
0.83 \\
0.85 \\
3.32 \\
0.56 \\
1.83 \\
0.78 \\
1.08\end{array}$ \\
\hline \multicolumn{3}{|c|}{$P<0.001$ highly significant } & $\begin{array}{r}\bar{x} 1 \cdot 198 \\
\text { S.E. } 0 \cdot 248 \\
t=4 \cdot 824\end{array}$ \\
\hline
\end{tabular}

This difference was reduced by treatment (Table III) to a value which was not significantly different from zero, but which was significantly $(P<0.01)$ more variable than that in the normal subjects. A significant $(P<0.01)$ diminution in the variability of the difference in blood flow was obtained by treating the patients.

Table III Blood flow in patients with rheumatoid arthritis after treatment (ml./min./100 ml.)

\begin{tabular}{|c|c|c|c|}
\hline \multirow[t]{2}{*}{ Patient no. } & \multicolumn{2}{|l|}{ Knee } & \multirow[t]{2}{*}{ Difference } \\
\hline & Involved & Non-involved & \\
\hline $\begin{array}{r}1 \\
2 \\
3 \\
4 \\
5 \\
6 \\
7 \\
8 \\
9 \\
10 \\
11\end{array}$ & $\begin{array}{l}2.07 \\
1.21 \\
1.49 \\
0.50 \\
1.12 \\
2.08 \\
0.59 \\
0.88 \\
1.64 \\
0.92 \\
2.07\end{array}$ & $\begin{array}{l}1.94 \\
1.22 \\
1.35 \\
0.55 \\
1.22 \\
1.68 \\
0.58 \\
0.72 \\
1.16 \\
0.95 \\
1.94\end{array}$ & $\begin{array}{r}0.13 \\
-0.01 \\
0.06 \\
-0.05 \\
-0.10 \\
0.40 \\
0.01 \\
0.16 \\
0.48 \\
0.03 \\
0.13\end{array}$ \\
\hline \multicolumn{3}{|c|}{$0.1>P>0.05$ not significant } & $\begin{array}{r}\bar{x} 0.107 \\
\text { S.E. } 0.055 \\
t=1.928\end{array}$ \\
\hline
\end{tabular}

In patients with osteoarthrosis (Table IV) there was little difference between the blood flow in the involved and non-involved knee. As in the normal subjects, the mean difference was not significantly different from zero $(P \doteqdot 0 \cdot 6)$.

Table IV Blood flow in patients with osteoarthrosis before treatment (ml./min./100 ml.)

\begin{tabular}{|c|c|c|c|}
\hline \multirow[t]{2}{*}{ Patient no. } & \multicolumn{2}{|l|}{ Knee } & \multirow{2}{*}{ Difference } \\
\hline & Involved & Non-involved & \\
\hline $\begin{array}{l}1 \\
2 \\
3 \\
4 \\
5 \\
6 \\
7 \\
8 \\
9\end{array}$ & $\begin{array}{l}1 \cdot 39 \\
1 \cdot 66 \\
1 \cdot 14 \\
1 \cdot 71 \\
1 \cdot 70 \\
1 \cdot 16 \\
1 \cdot 26 \\
1 \cdot 31 \\
0 \cdot 79\end{array}$ & $\begin{array}{l}1 \cdot 76 \\
1 \cdot 35 \\
1 \cdot 54 \\
1 \cdot 68 \\
1 \cdot 57 \\
0.90 \\
1 \cdot 00 \\
1 \cdot 08 \\
0.83\end{array}$ & $\begin{array}{r}-0.35 \\
0.31 \\
-0.40 \\
0.03 \\
0.13 \\
0.26 \\
0.26 \\
0.23 \\
-0.04\end{array}$ \\
\hline \multicolumn{3}{|c|}{$P \doteqdot \mathbf{0 . 6}$ not significant } & $\begin{array}{r}\bar{x} 0.047 \\
\text { S.E. } 0.088 \\
t=0.539\end{array}$ \\
\hline
\end{tabular}

In patients with osteoarthrosis no significant difference was observed as a result of treatment, either in the sample mean or in the variability Table V, (overleaf). 
Table $\mathrm{V}$ Blood flow in patients with osteoarthrosis after treatment ( $\mathrm{ml} . / \mathrm{min} . / 100 \mathrm{ml}$.)

\begin{tabular}{|c|c|c|c|}
\hline \multirow[t]{2}{*}{ Patient no. } & \multicolumn{2}{|l|}{ Knee } & \multirow[t]{2}{*}{ Difference } \\
\hline & Involved & Non-involved & \\
\hline $\begin{array}{l}1 \\
2 \\
3 \\
4 \\
5 \\
6 \\
7 \\
8 \\
9\end{array}$ & $\begin{array}{l}1.40 \\
1.22 \\
1.48 \\
1.60 \\
0.78 \\
1.58 \\
1.19 \\
1.24 \\
0.55\end{array}$ & $\begin{array}{l}1.76 \\
1.05 \\
1.47 \\
1.78 \\
0.46 \\
1.97 \\
0.82 \\
0.97 \\
0.78\end{array}$ & $\begin{array}{r}-0.36 \\
0.17 \\
0.01 \\
-0.18 \\
0.32 \\
-0.39 \\
0.37 \\
0.27 \\
-0.23\end{array}$ \\
\hline \multicolumn{3}{|c|}{$P \doteqdot \mathbf{0 . 5 0}$ not significant } & $\begin{array}{r}\bar{x} 0.002 \\
\text { S.E. } 0.099 \\
t=0.022\end{array}$ \\
\hline
\end{tabular}

\section{Discussion}

The rate of blood flow in a limb is very much influenced by physiological factors, chiefly the variations in the environmental temperature and the muscular activity preceding the measurement. Such variations, however, apply equally to both limbs and do not affect the difference between the two sides.

Fig. 1, showing the blood flow on different days in a normal subject, illustrates this point. When one of the joints is painful because of an inflammatory arthritis, a significant difference in the blood flow can be expected. Reduction of this difference by treatment can thus provide evidence of effective anti-inflammatory activity.

Fig. 2 shows how, in a patient with rheumatoid arthritis, treatment was followed after an initial difference by a return of the blood flow to about the same level on both sides.

Whitney (1953) pointed out that the calculation of the blood flow is based on the assumption that the limb investigated is circular in section, so that the method cannot be applied accurately over joints which are irregular in cross-section.

In this investigation, however, the absolute levels of blood flow are not important; it is the difference between the flow in an inflamed joint and that in its normal counterpart in the same patient that matters. The error resulting from the irregular shape of the joint applies to both sides.

In a few joints with large effusions, the blood flow measurement was performed before and immediately after aspiration and there was no significant change in the readings.

Although formal grading of activity on clinical grounds was not made, it was quite clear that subjective improvement took place in all eleven cases of rheumatoid arthritis corresponding to the reduction in blood flow.

It is interesting that most of the patients with osteoarthrosis claimed some subjective improvement after steroid injection, although there were no changes in the blood flow levels.

The results demonstrate that straingauge plethysmography can detect differences in blood flow in unilateral joint inflammation and that in this situation an objective assessment of the value of treatment is possible.

It seems likely that, if the physiological variations were to be eliminated (for example by subjecting the limb to a standard period of ischaemia), blood flow readings in a single joint might correlate with inflammatory activity. Further work is planned to investigate this point.

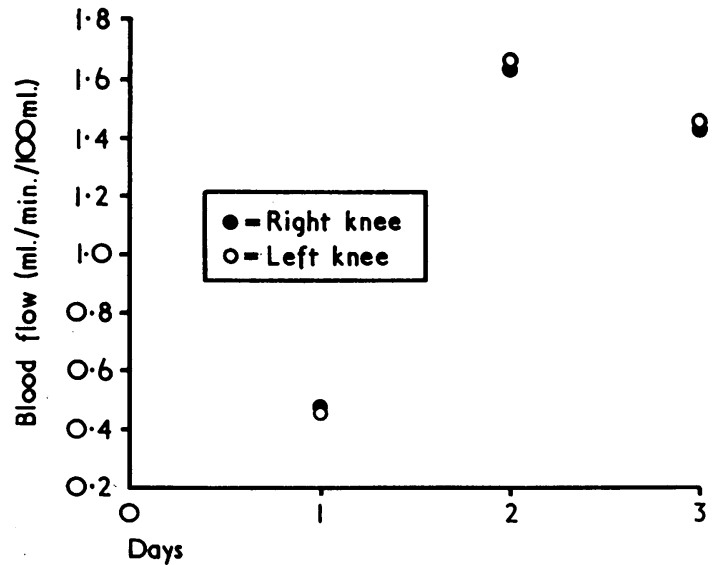

FIG. 1 Blood flow in a normal subject in right and left knees on 3 separate days.

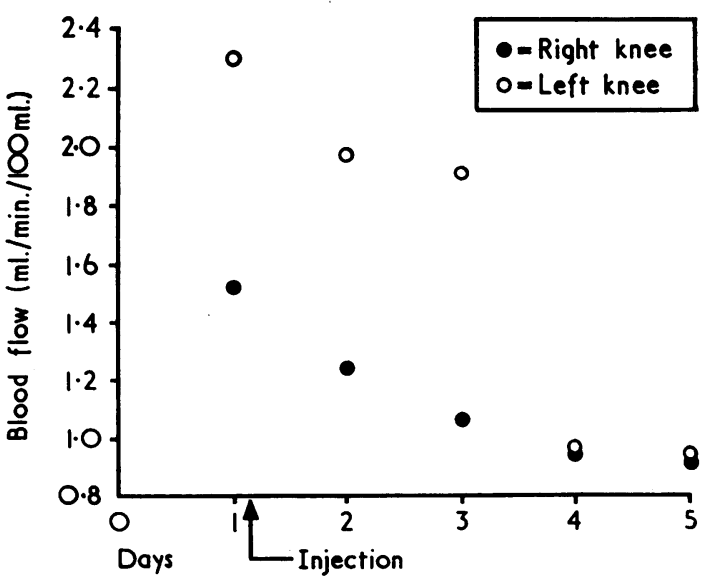

FIG. 2 Blood flow in a patient with rheumatoid arthritis with a painful left knee before and after steroid injection. 


\section{Summary}

To investigate the suitability of straingauge plethysmography in the assessment of inflammation in joints, the blood flow was measured in the knees of ten normal subjects, in eleven patients with rheumatoid arthritis, and in nine patients with osteoarthrosis with involvement of one knee only.

There was no difference in the blood flow between the two knees in the normal subjects, but the flow was significantly higher on the involved side in the patients with rheumatoid arthritis. This difference was reduced by treatment with an intra-articular steroid injection and at the same time clinical improvement took place.

No significant difference in blood flow was found between the involved and normal joints in patients with osteoarthrosis, and the readings were not altered by intra-articular steroid injection.

Straingauge plethysmography may well be a useful test in the assessment of joint inflammation and the efficacy of anti-inflammatory treatment.

I should like to thank Dr. R. Grahame, of the Department of Physical Medicine and Rheumatology, and Dr. A. Davis, of the Department of Physiology, at Guy's Hospital, for their help in the preparation of this paper.

\section{Discussion}

DR. A. ST. J. DIXoN (Bath) What does Dr. Vadasz mean by the knee?

DR. VADASZ The blood flows that I measure obviously do not refer to the whole knee. I am not quite sure exactly how much of the knee is being measured, but I think the distension of soft tissues around the knee joint is included. I am comparing two sides, the involved and non-involved, and I am offering these figures as an index of blood flow rather than of total blood flow through the whole joint. I am obviously not measuring flow through bone.

DR. A. ST. J. DIXON (Bath) It seems to me very likely that the tissues which are distending most quickly are the soft tissues outside the capsule of the joint rather than inside; the control experiment which might be very revealing is to put your plethysmographs round the knees of a patient in whom one ankle is inflamed and then to treat that ankle. I think you might find that this might also register as a difference in knee blood flow. In fact you might find that your plethysmograph would respond to inflammation almost anywhere in the limb below the cuff.

DR. M. I. V. JAYSON (Bath and Bristol) We have been using a conventional plethysmographic technique and have obtained rather similar results. What concerns us a little is that, as you pointed out, the Whitney straingauge depends very much on an even distribution in the expansion of tissues rather than a localized swelling at one point in the circumference round the mercury loop. In your experiment the swelling would presumably occur mainly on either side of the patella, so that the reproducibility of results would depend very much on the actual siting of the mercury loop. Can you be certain that the variability in the control measurements is not due to variation in positioning of the mercury loop?

DR. VADASZ While there is this theoretical criticism about joint shape, I mentioned that I tried the measurement before and after aspiration of a distended joint (where a more circular cross-section is reduced to a proper knee-shaped one), and I found no difference in the measurements. I conclude that, while there is a theoretical objection, the method is not sensitive enough to detect variations of shape, and I found it reproducible. In a normal subject the measurement was repeated five times on each knee in quick succession, removing and replacing the straingauge every time, and the results showed a very small variability.

DR. A. G. S. HILl (Stoke Mandeville) How much contribution do you think the skin makes to changes in circumference?

DR. VADASZ Quite a bit with an inflamed joint.

PROF. E. G. L. BYWATERS (London) One of the most unexpected graphs you showed was that demonstrating the diurnal variation from day to day was 0.4 to 1.6 , a 4-fold difference in this index of blood flow. If this can be substantiated it is really most surprising, and offers a very useful method of exploring that old legend that every one of our patients brings up about the weather and the rain and so on.

DR. VADASZ I was going to mention that there was a change in the weather; it was much hotter on the last two days of measurement. What we are measuring includes skin flow in the whole limb; but the two knees stayed together quite closely.

DR. W. W. BUCHANAN (Glasgow) I think it might be instructive to determine the extent to which this measurement depends on lymph flow and how much on synovial blood flow. It would be interesting to test how much an intra-articular injection of histamine affects the measurement. There is one point that I think should be made. You did state that, irrespective of what you were measuring, differences could be shown to be related to treatment, and this I think you have done.

PROF. J. J. R. DUTHIE (Edinburgh) It seems to me that you are measuring reactive hyperaemia and the effect thereon of an anti-inflammatory drug, which has nothing to do with the blood flow to the joint.

DR. VADASZ There is no reactive hyperaemia as such because the tourniquet is never inflated to above 60 $\mathrm{mm} / \mathrm{Hg}$ during the 10 seconds of compression.

PROF. E. G. L. BYWATERS (London) When we were doing plethysmography, measuring joint blood flow by displacement of synovial fluid from the cavity into a horizontal manometer, we used an arterial tourniquet distal to the knee joint. This would be one way of eliminating, for instance, ankle and distal skin flow.

DR. VADASZ I tried this and did not find much difference in the results. 


\section{References}

Boardman, P. L., AND HART, F. D. (1967) Brit. med. J., 4, 264 (Clinical measurement of the anti-inflammatory effects of salicylates in rheumatoid arthritis).

Dick, C., Dick, P. H., Nuki, G., Whaley, K., Boyle, J. A., Shenkin, A., Downie, W. W., and Buchanan, W. W. (1969) Ibid., 3, 278 (Effect of anti-inflammatory drug therapy on clearance of ${ }^{133} \mathrm{Xe}$ from knee joints of patients with rheumatoid arthritis).

HoRvath, S. M., AND HollaNDER, J. L. (1949) J. clin. Invest., 28, 469 (Intra-articular temperature as a measure of joint reaction).

Ropes, M. W., Bennett, G. A., CobB, S., JACox, R., and Jessar, R. A. (1959) Ann. rheum. Dis., 18, 49 (Diagnostic criteria for rheumatoid arthritis. 1958 revision).

Whitney, R. J. (1953) J. Physiol. (Lond.), 121, 1 (The measurement of volume changes in human limbs). 